\title{
A transporter-to-trap conversion: a disulfide bond formation in CRABP I mutant triggered by retinoic acid binding irreversibly locks the ligand inside the protein 1
}

\author{
Virginie Sjoelund and Igor A. Kaltashov \\ Department of Chemistry and Molecular and Cellular Biology Program, University of Massachusetts \\ at Amherst
}

\begin{abstract}
Transport proteins must bind their ligands reversibly to enable release at the point of delivery, while irreversible binding is usually associated with the extreme cases of ligand sequestration. Protein conformational dynamics is an important modulator of binding kinetics, as increased flexibility in the regions adjacent to the binding site may facilitate both association and dissociation processes. Ligand entry to, and exit from, the internal binding site of the Cellular Retinoic Acid Binding Protein I (CRABP I) occurs via a flexible portal region, which functions as a dynamic aperture. We designed and expressed a CRABP I mutant (A35C/T57C), in which a small-scale conformational switch caused by the ligand binding event triggers formation of a disulfide bond in the portal region, thereby arresting structural fluctuations and effectively locking the ligand inside the binding cavity. At the same time, no formation of the disulfide bond is observed in the apo-form of the mutant, and most characteristics of the mutant, including protein stability, are very similar to those of the wild type protein in the absence of retinoic acid. The mutation does not alter the kinetic of retinoic acid binding to the protein, although the disulfide formation makes the binding effectively irreversible, as suggested by the absence of retinoic acid transfer from the holo-form of the mutant to lipid vesicles in the absence of a reducing agent. Taken together, these data suggest that the disulfide bond formation in the portal region arrests large-scale structural fluctuations, which are required for retinoic acid release from the protein. The unique properties of the CRABP I mutant described in this work can be used to inspire and guide a design of nanodevices for multiple tasks ranging from sequestering small-molecule toxins both in tissue and circulation to nutrient-deprivation of pathogens.
\end{abstract}

\section{Keywords}

Cellular Retinoic Acid Binding Protein; Retinoic Acid; Mass spectrometry; disulfide bond; engineered protein; trap; nanomedicine

\begin{abstract}
Retinoic acid (RA), a metabolite of vitamin A exerts a wide variety of effects on vertebrate development, cellular differentiation and homeostasis (1-4). Clinically it is used for the treatment of skin disorders, the prevention of epidermal cancer and the treatment of acute promyelocytic leukemia (APL) $(5,6)$. RA modulates gene expression via binding to nuclear receptors, which belong to the steroid/thyroid hormone superfamily and act as transcription
\end{abstract}

\footnotetext{
${ }^{1}$ This work was supported by a grant from the National Institutes of Health GM R01-061666

Correspondence to: Igor A. Kaltashov.

Address correspondence to: Igor A. Kaltashov, University of Massachusetts, Department of Chemistry, 710 North Pleasant Street, Lederle Graduate Research Tower \#701, Amherst, MA 01003, Tel (413) 545-1460, Email kaltashov@ chem.umass.edu.
} 
factors (1,7-9). In addition, there are two low MW molecular weight intracellular proteins interacting with RA. These are the Cellular Retinoic Acid Binding Proteins (CRABP I and CRABP II), which belong to the family of the intracellular lipid-binding proteins (iLBPs). The functions attributed to CRABPs are to solubilize RA in the cytosolic environment and either transport it to the nuclear receptor site or modulate the amount of free RA available to the nuclear receptors by sequestering it in the cytosol $(10,11)$.

All members of the iLBP family are characterized by a conserved structure, which is formed by two orthogonal $\beta$-sheets (each composed of five anti-parallel $\beta$-strands) with a helix-turnhelix motif inserted between them. The $\beta$-barrel contains a poorly accessible hydrophobic ligand-binding cavity. Entry of RA into the cavity of CRABPI is believed to occur via a region of the protein comprising the $\beta \mathrm{C}-\mathrm{D}$ loop, the $\beta \mathrm{E}-\mathrm{F}$ loop and the N-terminal region of helix II (12). It is usually referred to as the portal region of CRABPand has been extensively studied in other members of the iLBP family, in particular in the fatty acid binding protein, by X-ray crystallography, mutational analysis and multidimensional NMR (13-16). NMR and mass spectrometric studies have shown that the backbone flexibility in the portal region of CRABP I is very significant (compared to the rest of the polypeptide chain) in the apo-form of the protein and decreases dramatically upon RA binding $(12,17)$. These observations support the notion that the portal region is dynamic in nature and undergoes rapid fluctuations, where transient loss of structure allows RA to enter the cavity housing the internal binding site, which is inaccessible in the static structure of the protein.

Recent studies of the Intestinal Fatty Acid Binding Protein (another member of the iLBP family), led to a suggestion that once the hydrophobic ligand has entered the binding cavity, it is kept within its confines via multiple contacts to residues on the $\alpha$-helix II and the $\beta \mathrm{C}-\mathrm{D}$ loop. Furthermore, comparison of the crystal structures of the apo and holo CRABPI showed that, upon binding, the $\beta \mathrm{C}-\mathrm{D}$ loop moves closer to the $\alpha$-helix II (18-20). However, the association process is reversible, as the non-covalent protein-ligand interactions only decrease, but do not completely eliminate, the transient unfolding events in the portal region, which now provide a route to complex dissociation. The main objective of the present work was to engineer a mutant whose conformational properties (both structure and dynamics) are indistinguishable from those of the wild type protein in the absence of the ligand, while the mobility in the portal region is eliminated in the holo-form. Since both passive and active RA transfers from CRABPs to RAR (21) are important elements in transcription modulation, availability of a CRABP mutant that freely binds the ligand, but fails to release it under physiological conditions, would be a valuable instrument in our ongoing studies of the receptor-transporter interactions.

We hypothesized that if we could physically arrest fluctuations in the portal region and effectively lock the protein in the holo-conformation, RA would not be able to escape from the internal cavity. We found two residues, located in the $\alpha$-helix II and in the $\beta C$-D loop, that upon mutation to cysteines could form a disulfide bond only in the holo-form, thus creating a covalent cross-link, which cements the holo-conformation of the protein, thereby preventing RA exit from the binding cavity. While the oxidation of the two strategically placed cysteine residue occurs readily in the holo-form of CRABP I, no disulfide bond forms in the absence of the ligand, as the geometry of the apo-conformation of the protein does not allow the two thiol groups to interact. The selective ability of this mutant to form a conformation-constraining cross-link only following the ligand binding event allows RA to be locked inside the protein cavity without obstructing its entry to the binding site. In addition to providing further support for the portal model of CRABP-RA interaction, the results of this work can be used to inspire design of therapeutic agents with precisely tuned properties for multiple tasks in nanomedicine ranging from sequestering small-molecule toxins both in tissue and circulation to nutrientdeprivation of pathogens. 


\section{Materials and methods}

\section{Bacterial strains and plasmids}

A previously constructed plasmid, pET-CRABP I (18), containing the CRABP I gene subcloned in the $E$. coli expression vector pET-16b (Novagen, Sand Diego, Ca) was used for site-directed mutagenesis and over-expression of both the wild type and the mutant CRABP I. The pET-16b vector contains an N-terminal His-tag, a short linker with a Factor Xa cleavage site. E. coli $\mathrm{DH} 5 \alpha$ was used as the host strain for propagating the recombinant plasmids carrying the CRABP I wild type and mutant gene. E. coli BL21 (DE3) having a copy of the T7 RNA polymerase gene on its chromosome was used as the host strain for overexpression of both the wild type and mutant CRABP I.

\section{Site directed mutagenesis}

The A35C/T57C mutant was constructed by site directed mutagenesis using the inverse-PCR method (22). The oligonucleotides (Integrated DNA Technologies, Coralville, IA), templates and mutant constructed are shown in Supporting Material. The PCR reactions $(50 \mu \mathrm{L})$ consisted of $50 \mathrm{ng}$ of the DNA template (50 ng), $0.25 \mu \mathrm{M}$ forward primer, $0.25 \mu \mathrm{M}$ reverse primer, 25 $\mu \mathrm{M}$ of each DNTP (Gibco BRL, Carlsbad, CA), 1X PfuI buffer (Stratagene, La Jolla, CA), and 2.5 units $P f u$ I polymerase (Stratagene) and were subjected to the following program; denaturation $\left(95^{\circ} \mathrm{C}, 1 \mathrm{~min}\right)$, amplification $16 \times\left(\left(95^{\circ} \mathrm{C}, 30 \mathrm{~s}\right)\left(55^{\circ} \mathrm{C}, 1 \mathrm{~min}\right)\left(68^{\circ} \mathrm{C}, 13 \mathrm{~min}\right)\right)$, and extension $\left(68^{\circ} \mathrm{C}, 30 \mathrm{~min}\right)$. At the end of the PCR cycle, $45 \mu \mathrm{L}$ of the product was digested with $D p n I$ at $37{ }^{\circ} \mathrm{C}$ for 1 hour. Both the digested and non-digested DNA was loaded on a $1 \%$ agarose gel with a band corresponding to the full-length plasmid $(6.4 \mathrm{~kb})$ present as the only significant product. The DNA was used to transform the E. coli strain DH5 $\alpha$, which was plated onto LB agar containing $0.1 \mathrm{mg} / \mathrm{mL}$ ampicilin. The plasmids from the transformants was extracted using the QIAprep Spin Miniprep Kit (QIAGEN, Valencia, CA) and checked by DNA sequencing whether the plasmids have incorporated the right mutation and have maintained fidelity throughout the rest of the gene sequence.

\section{Protein expression}

Wild-type CRABPI and CRABPI-A35C/T57C was expressed in E. coli BL21 (DE3) cells. Expression cultures ( $1 \mathrm{~L}$ of LB medium supplemented with $1 \mu \mathrm{g} / \mathrm{mL}$ ampicilin) inoculated from a culture grown to an $\mathrm{OD}_{600}$ of 1.0 at a 1:25 dilution were grown at $37^{\circ} \mathrm{C}, 250 \mathrm{rpm}$, until the $\mathrm{OD}_{600}$ reached $\approx 0.7$. Protein expression was induced with $0.4 \mathrm{mM} \mathrm{IPTG}$ for 3 hours at $37^{\circ} \mathrm{C}$ for wild type CRABPI and $30^{\circ} \mathrm{C}$ for the $\mathrm{A} 35 \mathrm{C} / \mathrm{T} 57 \mathrm{C}$ mutant. The protein purification process has been described elsewhere (18).

\section{Circular dichroism}

The CD spectra were measured with a Jasco J-715 spectropolarimeter (Jasco, Tokyo, Japan). Solutions with a protein concentration of $10 \mu \mathrm{M}$ in $10 \mathrm{mM}$ sodium phosphate buffer $(\mathrm{pH} 8.0)$ were placed in a $1 \mathrm{~mm}$ quartz cuvette for far UV experiments (195 to $250 \mathrm{~nm}$ ). Each spectrum was obtained by scanning this range with a $0.5 \mathrm{~nm}$ increments at a $20 \mathrm{~nm} / \mathrm{min}$ rate; five runs were averaged for each spectrum to ensure adequate signal-to-noise ratio. After buffer baseline subtraction, the $\mathrm{CD}$ data were normalized to protein concentration and are expressed as molar residue ellipticity.

\section{Membranes}

1,2-Dioleoyl-sn-Glycero-3-Phosphocholine (DOPC) was obtained from Avanti Polar Lipids (Alabaster, AL). Small unilamellar vesicles of DOPC were prepared by sonication. DOPC in chloroform was pipetted into a glass tube and the solvent evaporated under a stream of nitrogen. The lipid film was further dried under vacuum for $30 \mathrm{~min}$. The lipids were resuspended in 
buffer containing $10 \mathrm{mM}$ Tris and $100 \mathrm{mM} \mathrm{NaCl}(\mathrm{pH} 8.0)$ and the suspension was sonicated until clarity.

\section{Fluorescence titrations}

The binding properties of the mutant protein were measured using a fluorimetric titration method (23) (FelixX32, PTI, Lawrenceville, NJ). The wild type and mutant proteins ( $1 \mu \mathrm{M}$ in $10 \mathrm{mM}$ Tris buffer, $\mathrm{pH} 8.0$ ) were excited at $280 \mathrm{~nm}$ and the emission spectra recorded in the 300 to $380 \mathrm{~nm}$ range ( $2 \mathrm{~nm}$ slit width). Concentrated RA solution in ethanol was added to the protein solutions in $3 \mu \mathrm{L}$ aliquots. The final volume of added ethanol did not exceed $1.7 \%$ of the protein solution total volume. Concentration of RA stock was determined spectrophotometrically using a molar absorption coefficient of $45000 \mathrm{M}^{-1} \cdot \mathrm{cm}^{-1}$ at $336 \mathrm{~nm}$ (23).

\section{Rate of association of retinoic acid with CRABPI A35C-T57C}

Solutions of apo-CRABP I and apo-CRABP I mutant A35C-T57C ( $1 \mu \mathrm{M}$ each in a buffer containing $10 \mathrm{mM}$ Tris, $\mathrm{pH}$ 8.0) were placed in fluorescence cuvettes. Retinoic acid from a 1 $\mathrm{mM}$ stock was added to each cuvette to a final concentration of $1 \mu \mathrm{M}$, and the fluorescence intensity at $328 \mathrm{~nm}$ (excitation at $280 \mathrm{~nm}$ ) was followed at $1.45 \mathrm{~s}$ time intervals until the equilibrium was reached.

Binding of RA to the protein is a second order reaction, whose rate can be expressed as $k_{\mathrm{ON}}$. [protein].[RA]. If the initial concentrations of the two binding partners are equal to each other (i.e., $\left.[\text { protein }]_{o}=[\mathrm{RA}]_{0}=1 \mu \mathrm{M}\right)$, then

$$
\frac{1}{R A}-\frac{1}{R A_{0}}=k_{\text {on }} t
$$

Concentration of free [RA] in solution can be calculated at any point in time using the fractional concentrations of the apo- and holo-forms of the protein:

$$
\alpha=\frac{F_{\text {apo }}-F}{F_{\text {apo }}-F_{\text {holo }}}
$$

where $\mathrm{F}_{\text {holo }}, \mathrm{F}_{\mathrm{apo}}$ are fluorescence intensities of the end points of the ligand binding reactions (i.e. the apo- and holo- proteins). $\mathrm{F}$ is the fluorescence of the protein at a given retinoic acid concentration. The fluorescence data sets were fitted using equations (1) and (2) to obtain the $k_{\mathrm{ON}}$ value of the association reaction.

\section{Rate of transfer of retinoic acid between CRABPI A35C-T57C and vesicles}

A reduced mixture of CRABP I mutant A35C/T57C with retinoic acid (1:1 molar ratio) was mixed in a cuvette with $3.2 \mathrm{mM}$ DOPC vesicles in a buffer containing $10 \mathrm{mM}$ Tris, $100 \mathrm{mM}$ $\mathrm{NaCl}$ and $1 \mathrm{mM} \mathrm{BME}, \mathrm{pH}$ 8.0. The final volume of the mixture was $1 \mathrm{~mL}$. Fluorescence intensity at $328 \mathrm{~nm}$ (excitation at $280 \mathrm{~nm}$ ) was followed at $5 \mathrm{~s}$ time intervals until the equilibrium was reached. Since the dissociation reaction follows first order kinetics with a rate constant $k_{\mathrm{OFF}}$, the latter could be obtained by fitting the fluorescence data set to the following equation:

$$
\ln \left(F_{\text {apo }}-F\right)=-k_{\mathrm{OFF}} \cdot t
$$

\section{Distribution of retinoic acid between CRABP I A35C/T57C and DOPC vesicles}

Mixtures of reduced and non-reduced CRABP I A35C/T57C with retinoic acid (1:1 molar ratio) were mixed in cuvettes with DOPC vesicles (the DOPC concentration in solution was $3.2 \mathrm{mM}$ ) in a buffer containing $10 \mathrm{mM}$ Tris, $100 \mathrm{mM} \mathrm{NaCl}$ and $1 \mathrm{mM}$ BME to a final volume 
of $100 \mu \mathrm{L}$. The intensity of the fluorescence signal was monitored at $328 \mathrm{~nm}$ for $5 \mathrm{~min}$ at equilibrium every $5 \mathrm{~s}$ (excitation at $280 \mathrm{~nm}$ ). The amount of RA present in the vesicles versus in the protein was obtained by calculating the theoretical fluorescence for the apo- and holoforms in the presence of small unilamellar vesicles (SUV).

$$
\begin{aligned}
& F_{\text {apo }}^{S U V}=F_{\text {SUV }}+F_{\text {apo }}-F_{\text {buffer }} \\
& F_{\text {holo }}^{S U V}=F_{\text {SUV }}+F_{\text {apo }}-F_{\text {buffer }}
\end{aligned}
$$

where, $F_{\text {SUV }}, F_{\text {apo }}$ and $F_{\text {holo }}$ are the fluorescence of the SUV alone, of the apo-form in the absence of SUV and that of the holo-form in the absence of SUV respectively.

The fraction of RA transferred from the protein to the vesicles can be calculated as

$$
\alpha=\frac{F_{\text {apo }}^{S U V}-F^{S U V}}{F_{\text {apo }}^{S U V}-F_{\text {holo }}^{S U V}}
$$

where $F^{\mathrm{SUV}}$ is fluorescence intensity in the presence of SUV.

\section{Peptide mapping and disulfide detection/localization}

The apo- and holo-forms of the mutant CRABP were treated with an excess of iodoacetic acid (Acros Organics, Morris Plains, NJ) for 90 min, in the dark, at room temperature to protect any free cysteines. The reaction was ended by removing the excess iodoacetic acid by running the protein through a desalting column. Immobilized TPCK (L-(tosylamido-2-phenyl)-ethylchloromethyl) trypsin was obtained from Pierce Biotechnology Inc. (Rockford, IL) and washed 3 times with $100 \mathrm{mM} \mathrm{NH} \mathrm{HCO}_{3} / \mathrm{NH}_{4} \mathrm{OH}$ solution at $\mathrm{pH} 8.0$ prior to digestion. Protein digestion was initiated by dispersing the immobilized trypsin in $50 \mu \mathrm{M}$ apo- or holo-CRABP I A35C/T57C solutions in $100 \mathrm{mM} \mathrm{NH}_{4} \mathrm{HCO}_{3}$ (pH 8.0). Digestion was carried out for 3 hours at $37{ }^{\circ} \mathrm{C}$ in the dark (to protect RA from possible photoisomerization). Proteolysis was stopped by removing the immobilized TPCK from the protein solution by centrifugation and subsequent freezing of the supernatant.

Masses of tryptic fragments of CRABP I A35C/T57C were obtained with a Qstar-XL (ABISciex, Foster City, Ca) hybrid quadrupole/time-of-flight mass spectrometer in the positive ion mode. The tryptic peptide solutions were continuously infused into the TurboSpray ${ }^{\mathrm{TM}}$ source at a flow rate of $5 \mu \mathrm{L} / \mathrm{min}$. Presence of a disulfide bond-linked peptide dimer among the proteolytic fragments was detected by using collision-activated dissociation (CAD) in the negative ion mode following mass-selection of a precursor ion. Stability of protein-RA complexes in the gas phase was evaluated by monitoring the extent of complex dissociation as a function of de-clustering potential (DP) in the ESI interface (10 to 60V).

\section{Results}

\section{Rationale of mutant design}

The crystal structures of the apo and holo-CRABP I show that ligand binding does not result in a large conformational change. However, the portal model of RA binding suggests that the protein-ligand association event triggers relatively small-scale repositioning of several segments including helices $\alpha \mathrm{I}, \alpha \mathrm{II}$ and turns between $\beta \mathrm{C}-\beta \mathrm{D}$ and $\beta \mathrm{E}-\beta \mathrm{F}(18,22)$. We used the crystal structures of the holo- and apo-forms of CRABP I to search for residues within and/or near the portal-region that are distant from each other in the apo-form (1CBI), but are brought in close proximity as a result of the conformational re-adjustment following RA binding (1CBR). The proximity should be close enough to afford formation of a disulfide bond, should each of these two residues be mutated to a cysteine. The amino acid sequence of the wild type 
CRABP I was screened to identify such a residue pair(s) using the geometry-based disulfide by design program (23). Among all possible combinations, only pairs located on two different segments of the protein, one located in the portal region, were considered. Pairs capable of forming a disulfide bond both in the apo and holo-forms were also eliminated. That left only one pair (A35 on helix $\alpha \mathrm{II}$ and T57 on the turn $\beta \mathrm{C}$ - $\beta \mathrm{D}$ ) (Fig. 1). These two residues are in close enough proximity in the holo-form to form a disulfide bond, but not in the apo-form. It is noteworthy that neither A35, nor T57 are involved in interactions with the ligand.

\section{Expression and purification of the mutant protein}

The CRABPI A35C/T57C mutant was constructed in a CRABP I wild-type (wt) background that contained an N-terminal His tag to facilitate its purification (see the Supporting Material section). As was the case for the wt-CRABP I, the mutant over-expressed well in Escherichia Coli and partitioned to the cytoplasm rendering the purification a one-step process using a NiNTA column. A typical yield for both the $w t$-CRABP I and the mutant protein was of $30 \mathrm{mg} /$ $\mathrm{L}$ and $20 \mathrm{mg} / \mathrm{mL}$ cell culture respectively.

\section{CD spectra correspond to $\beta$-sheet proteins}

Far-UV CD spectra for both $w t$ and mutant CRABP I show a minimum at $216 \mathrm{~nm}$ and a maximum at about $197 \mathrm{~nm}$ (figure 2A), which is characteristic of $\beta$-sheet proteins. In addition, the CD spectra for WT shows a trough at $228 \mathrm{~nm}$, which has been shown to arise from fine details in the tertiary structure surrounding W87 and W109 (24). These characteristics are also present in our mutant protein. When the protein is complexed with RA in the presence or absence of a reducing agent (see Supporting Material), there is no significant change in the CD spectra indicating that the mutation, whether the protein is in an apo- or holo-form, does not induce significant changes in its secondary structure.

\section{Stoichiometry of RA binding to CRABP I is not affected by the mutation}

In order to ascertain that the mutant retained the ability to bind RA, fluorescence titrations were carried out for both wt-CRABP I and the A35C/T57C mutant. The intrinsic fluorescence of various retinoid-binding proteins, including CRABP I, decreases upon ligand binding due to the overlap from the fluorescence emission bands of tryptophan and tyrosine side chains and the absorption bands of retinoids. Consequently, if a tryptophan side chain is positioned in the vicinity of the ligand binding site, fluorescence quenching ensues upon ligand binding. This phenomenon has been extensively studied and used to monitor binding of retinoids to a variety of proteins, including CRABP I (23-27). The mutant CRABP I binds retinoic acid with at the same stoichiometry as $w t$-CRABP I (Figure 2B). Both the WT and the mutant protein are 50\% in the holo-form at a concentration of RA that is $50 \%$ of that the protein, showing that no RA is free, and thus a binding stoechiometry of $1: 1$. Since the protein concentration used is significantly above published $K_{d}$ values, this data cannot be used to measure the $K_{d}$ of the reaction.

\section{Unfolding of the mutant is cooperative and reversible in the absence of RA}

To examine whether the double mutation altered the global conformational stability of CRABP I, the sensitivity of the mutant to urea-induced denaturation was determined. Urea-induced unfolding of CRABP I is associated with a red shift in the emission spectra of the protein and an increase in the fluorescence intensity (Figure 2D). Previous work has shown that the presence of the His-tag does not perturb the structure (18). The mutant unfolded cooperatively and refolded reversibly (Figure 2C). The equilibrium data are well described by a two-state folding process (28). The urea sensitivity of the mutant is essentially the same as that of $w t$ CRABP I, strongly suggesting that the double mutation did not affect the overall conformational stability of the protein (Table 1 ). 


\section{Formation of a de novo disulfide bond in the holo-form of the double mutant}

In order to verify a disulfide bond formation between the two introduced cysteine residues following RA binding to the double mutant, disulfide mapping was carried out both in the presence and the absence of retinoic acid in the protein solution. The protein was treated with iodoacetic acid, followed by trypsin digestion and ESI MS analysis of the masses of the proteolytic fragments. The tryptic digest of the double mutant in the absence of RA contained nineteen peptides, sixteen of which were at least three amino acid residues long and were easily assigned (see Supporting Material for more detail). Two of these peptides (T7 and T9) were notably absent in the digest of the protein treated with iodoacetic acid in the presence of RA. Instead, an additional species was present, whose mass corresponded to a peptide dimer T7/ T9 linked by a disulfide bond (Figure 3). The identity of this species and the presence of a disulfide bond were verified by fragmenting it in the negative ion mode. Unlike collisioninduced dissociation (CAD) of peptide cations, fragmentation in the negative ion mode usually leads to facile dissociation of disulfide bonds, resulting in highly recognizable "signature" dissociation patterns of peptide oligomers containing external disulfide cross-links $(20,29)$. Figure 4 shows the CAD spectrum of a di-anionic species at $\mathrm{m} / \mathrm{z}$ 1070.6001, where the three major groups of fragment ions represent anionic species corresponding to $\mathrm{T} 7$ and $\mathrm{T} 9$ segments of the protein, unequivocally confirming identification of this tryptic peptide as a disulfidelinked T7/T9.

\section{The double mutant traps retinoic acid inside the binding cavity under non- reducing conditions}

Rate of association of retinoic acid with CRABP I A35C/T57C: The rate constant of association of retinoic acid with CRABPI A35C-T57C $\left(k_{\mathrm{ON}}\right)$ was measured by utilizing the quenching effect of retinoic acid on the protein upon binding (23). Retinoic acid was dissolved in ethanol and mixed with $w t$-CRABP I and the mutant. The fluorescence of each mixture at $328 \mathrm{~nm}$ (excitation at $280 \mathrm{~nm}$ ) was monitored at $1.45 \mathrm{~s}$ intervals until the equilibrium was reached. Since the initial concentrations of both the protein and retinoic acid in these experiments were the same, and the binding stoichiometry is 1:1 for both wild type protein and the mutant (vide supra), the second order rate constants of protein-ligand association can be obtained by plotting $1 /[\mathrm{RA}]_{\mathrm{t}}-1 /[\mathrm{RA}]_{0}$ as a function of time (Figure $5 \mathrm{~A}$ ). No significant difference in the binding kinetics was observed between $w t$-CRABP I and the double mutant, suggesting that the mutation has no effect on the binding kinetics of retinoic acid into the cavity of the protein (Figure 5B). Furthermore, addition of the reducing agent to the mixture of RA and the double mutant had no effect on the binding kinetics. The $k_{\mathrm{ON}}$ values obtained in this experiment are as follows: $(61.1 \pm 0.8) \times 10^{6}\left(\mathrm{M}^{-} \cdot \min \right)^{-1}$ and $(61.4 \pm 0.7) \times 10^{6}(\mathrm{M} \cdot \mathrm{min})^{-1}$ respectively for the wild type and the mutant protein in the absence of the reducing agent and $(61.2 \pm 1.1) \times 10^{6}(\mathrm{M} \cdot \mathrm{min})^{-1}$ and $(60.2 \pm 1.1) \times 10^{6}(\mathrm{M} \cdot \mathrm{min})^{-1}$ for the wild type and the mutant protein in the presence of $0.1 \mathrm{mM}$ TCEP. These results clearly indicate that the side chains of the introduced cysteine residues do not interfere with the ligand entry into the cavity in the apo-form of the double mutant.

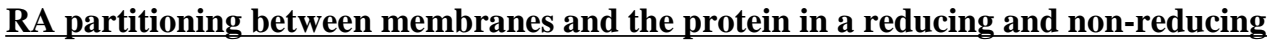
environment: Poor solubility of RA in water makes it difficult to monitor its dissociation from CRABP I in aqueous environments. In order to avoid this problem, RA dissociation from the double mutant of CRABP I was monitored in the presence of a "hydrophobic sink", that was chosen to be unilamellar DOPC vesicles. This system has been previously used to monitor the dissociation of the CRABPs/RA complexes (10) and of retinoid binding proteins/retinoids in general $(26,30,31)$. Since the presence of vesicles had no effect on the intrinsic fluorescence of the protein (see Supplementary Material for more detail), RA transfer from the protein to the vesicles could be followed by monitoring the increase in fluorescence of the protein. These experiments do not aim at measuring the $\mathrm{k}_{\text {off }}$ value but ascertaining whether RA partitions 
from the protein to the vesicles. The fluorescence change is shown in Figure 6A. In the presence of $1 \mathrm{mM} \mathrm{BME}$, the fluorescence after $10 \mathrm{~min}$ is indistinguishable from that of the protein in its apo-form. Without a reducing agent, the fluorescence after $10 \mathrm{~min}$ remains at level of the holo-form. The amount of the apo-protein in the presence of the reducing agent is $(96.3 \pm 1.1) \%$ and in the absence of reductant is $(4.1 \pm 0.6) \%$ (Figure $6 \mathrm{~B})$. The disulfide bond present in the holo-form efficiently "traps" retinoic acid in the binding cavity on the time scale of these experiments.

Since RA does not dissociate from the double mutant in the absence of the reducing agent, measurement of $k_{\mathrm{OFF}}$ had to be done under reducing conditions (Figure 7 ). The measured off rate is of $0.311 \pm 0.004 \mathrm{~min}^{-1}$, which is in good agreement which previous published results for the wild type protein (32). The resulting apparent $\mathrm{K}_{\mathrm{d}}$ for the reduced form of the double mutant is of $5.2 \mathrm{nM}$, which is in the range of previous reported values $(33,34)$.

Increased stability of the mutant protein-ligand complex in the gas phase: Previously we demonstrated that RA-CRABP I complex is only marginally stable in the gas phase and dissociates readily in the ESI interface, presumably due to the significant role played by the hydrophobic interactions in maintaining the complex integrity (35). In this work the effect of the double mutation on the stability of the protein-ligand complex was probed by monitoring the extent of dissociation as a function of the de-clustering potential in the ESI interface simultaneously for both $w t$-CRABP I and the double mutant. The results of these measurements (Figure 8) suggest that the double mutation results in a significant increase of the fraction of surviving protein-ligand complexes even at high de-clustering potential. Since RA dissociation in the gas phase is likely to involve (partial) unfolding of the host protein as a required step, the double mutation clearly enhances the protein conformational stability even in the absence of solvent.

\section{Discussion}

The mechanisms of retinoic acid interaction with CRABPs have been the subject of extensive studies by X-ray crystallography (19), nuclear magnetic resonance (12)and mass spectrometry (17). These studies and those done on members of the iLBP family $(13,36-44)$ have provided detailed information concerning the structure of the ligand-binding site, conformation of the $\beta$-barrel backbone side chains and the dynamic motions of the protein essential for retinoic acid entrance into the cavity. These studies lead to a hypothesis that the region surrounding the $\beta \mathrm{C}-\mathrm{D}$ loop, the $\beta \mathrm{E}-\mathrm{F}$ loop and the $\mathrm{N}$-terminal region of helix II serve as an entry/exit port for the ligand (the so-called portal region hypothesis). This hypothesis gained further support from several studies aimed at modulating the kinetics of RA entry into the binding cavity by mutating residues in the portal region to increase the channel diameter $(14,45,46)$. The objective of this study was different, as we sought to modulate the ligand-binding properties of CRABP I (more specifically, ligand exit from the cavity) by inhibiting the ligand exit from the cavity without affecting the entrance to the binding site. To achieve this objective, we engineered a CRABP I mutant in which the initial RA binding event triggers an irreversible covalent modification. This modification (cross-linking) arrests the large-scale dynamic motions of the protein backbone in the portal region, thereby preventing RA from exiting the binding cavity.

The residues mutated in this study were selected for several reasons. Crystal structure analysis of CRABP I in the apo- and holo-forms has shown that there is very few differences between the two conformations (19). The most significant one is the difference in the position of helix II with respect to the $\beta \mathrm{C}-\mathrm{D}$ loop. The residues A35 (helix II) and T57 ( $\beta \mathrm{C}-\mathrm{D}$ loop) are not involved in ligand binding, although both appear to be highly conserved within the i-LBP family. A35 is conserved in 19 proteins (36.5\%) and T57 is conserved in 36 proteins (69.2\%) among the fifty-two iLBP family members and the non-conserved residues also have small 
side chains. (A35 is replaced by L ( 9 proteins), $\mathrm{V}$ ( 4 proteins), $\mathrm{T}$ (10 proteins), I ( 7 proteins) and $\mathrm{D}$ ( 3 proteins), and $\mathrm{T} 57$ by $\mathrm{P}$ (4 proteins), A (6 proteins), $\mathrm{G}$ (3 proteins) and $\mathrm{N}$ (1 protein)). Not surprisingly, substituting A35 and T57 in the CRABP I sequence with cysteine residues does not interfere with RA entry into the binding cavity, as the thiol side chains are too small to create any steric hindrance in the portal region and are pointing towards the outside of the protein. At the same time, a minor conformational adjustment in the portal region following RA binding to the protein brings the two residues in close enough proximity to afford a disulfide bond formation between the two newly introduced cysteine residues. Formation of the disulfide bond in the holo-form and its absence in the apo-form of the double mutant was confirmed by mass spectrometric methods.

While the mutations did not exert a significant influence on the protein stability in the absence of the ligand and its association rate, the disulfide bond formation prevented RA exit the protein cavity in the absence of a reducing agent. When the latter was added to the holo-protein solution, the off rate was similar to that of the wild-type protein. Interestingly, the apo-mutant form could refold back to its native conformation whereas the denatured holo-form of the protein could not be refolded back to its native conformation as shown by fluorescence spectroscopy. It is likely that the presence of a disulfide bond in the double mutant disturbs the protein energy landscape significantly enough to introduce a misfolded state acting as a kinetic trap. It remains to be seen whether the oxidized form of the refolded double mutant has a single conformation or is an ensemble of several conformations. This observation is very intriguing, since the previous studies of CRABP I folding showed that the helical segments were the first elements of higher order structure to form (following less than $300 \mu \mathrm{s}$ ), only to be followed later by the formation of the $\beta$-sheets (on the $100 \mathrm{~ms}$ scale) $(18,47)$. It seems plausible that once the helices are formed, the disulfide bond locks the protein in an energetically favorable conformation that does not allow the $\beta$-sheets to form, trapping the protein in the misfolded state.

Despite its inability to properly fold from the denatured state, the ligand-bound oxidized form of the double mutant is remarkably stable and displays superior ligand-binding properties (compared to wt-CRABP I) even in the absence of solvent. While several mutants have been designed in the past based on the iLBP template, modulation of the ligand binding affinity was achieved by adjusting the steric hindrance at the protein aperture leading to the internal cavity or by mutating residues interacting with RA in the ligand binding pocket. The double mutant presented and investigated in this work is unique in that the ligand locking in the binding cavity is achieved by arresting the dynamic fluctuations in the portal region.

The emergence of nanomedicine and molecular therapeutics in recent years resulted in a surge of interest in designing macromolecules with precisely controlled properties. Although the majority of work in this field is now focused on nanocarriers as drug delivery vehicles (48), significant efforts are also invested towards designing constructs inspired by protein cage architectures, such as viral capsids $(49,50)$. The approach presented in this work may be used to design highly specific and efficient sequestering agents for small molecules. The ligand trapping is irreversible due to formation of a covalent cross-link, which is triggered by the binding event itself. Since the release of the ligand and recycling of the "transporter-turnedtrap" protein is only possible under reducing conditions, systems similar to the one presented in this work may also be used in biotechnological applications that require highly efficient mono-directional transport of small molecules (e.g., bioreactor-based manufacturing). Finally, the successful engineering of a CRABP I mutant that converts a transport protein to a trap provides a conclusive evidence of validity of the portal hypothesis of ligand binding to proteins from the iLBP family. 


\section{Supplementary Material}

Refer to Web version on PubMed Central for supplementary material.

\section{Acknowledgements}

The authors are grateful to Prof. Lila M. Gierasch for providing the $w t$-CRABP I plasmid.

\section{Abbreviations}

CRABP

Cellular Retinoic Acid Binding Protein

RAR

Retinoic Acid Receptor

RA

Retinoic Acid

IFABP

Intestinal Fatty Acid Binding Protein

iLBP

Intracellular Lipid Binding Protein

MS

Mass Spectrometry

ESI

Electrospray Ionization

DOPC

1,2-Dioleoyl-sn-Glycero-3-Phosphocholine

CD

Circular Dichroism

IPTG

Isopropyl $\beta$-D-1-thiogalactopyranoside

LB

Lubia Broth

CAD

Collision Activation Dissociation

BME

beta-mercaptoethanol

SUV

Small Unilamellar Vesicles

TCEP

Tris(2-Carboxyethyl) phosphine

\section{References}

1. Chambon P. A decade of molecular biology of retinoic acid receptors. Faseb J 1996;10:940-954. [PubMed: 8801176]

Biochemistry. Author manuscript; available in PMC 2008 November 20. 
2. Ross SA, McCaffery PJ, Drager UC, De Luca LM. Retinoids in embryonal development. Physiol Rev 2000;80:1021-1054. [PubMed: 10893430]

3. Ruhl R, Plum C, Elmazar MM, Nau H. Embryonic subcellular distribution of 13-cis- and all-transretinoic acid indicates differential cytosolic/nuclear localization. Toxicol Sci 2001;63:82-89. [PubMed: 11509747]

4. Noy N. Retinoid-binding proteins: mediators of retinoid action. Biochem J 2000;348(Pt3):481-495. [PubMed: 10839978]

5. Roos TC, Jugert FK, Merk HF, Bickers DR. Retinoid metabolism in the skin. Pharmacol Rev 1998;50:315-333. [PubMed: 9647871]

6. Chomienne C, Fenaux P, Degos L. Retinoid differentiation therapy in promyelocytic leukemia. Faseb J 1996;10:1025-1030. [PubMed: 8801163]

7. Borghi R, Vene R, Arena G, Schubert D, Albini A, Tosetti F. Transient modulation of cytoplasmic and nuclear retinoid receptors expression in differentiating human teratocarcinoma NT2 cells. $\mathrm{J}$ Neurochem 2003;84:94-104. [PubMed: 12485405]

8. Mark M, Ghyselinck NB, Wendling O, Dupe V, Mascrez B, Kastner P, Chambon P. A genetic dissection of the retinoid signalling pathway in the mouse. Proc Nutr Soc 1999;58:609-613. [PubMed: 10604193]

9. Sun SY, Yue P, Mao L, Dawson MI, Shroot B, Lamph WW, Heyman RA, Chandraratna RA, Shudo K, Hong WK, Lotan R. Identification of receptor-selective retinoids that are potent inhibitors of the growth of human head and neck squamous cell carcinoma cells. Clin Cancer Res 2000;6:1563-1573. [PubMed: 10778990]

10. Dong D, Ruuska SE, Levinthal DJ, Noy N. Distinct roles for cellular retinoic acid-binding proteins I and II in regulating signaling by retinoic acid. J Biol Chem 1999;274:23695-23698. [PubMed: 10446126]

11. Venepally P, Reddy LG, Sani BP. Analysis of the effects of CRABP I expression on the RA-induced transcription mediated by retinoid receptors. Biochemistry 1996;35:9974-9982. [PubMed: 8756459]

12. Krishnan VV, Sukumar M, Gierasch LM, Cosman M. Dynamics of cellular retinoic acid binding protein I on multiple time scales with implications for ligand binding. Biochemistry 2000;39:91199129. [PubMed: 10924105]

13. Hodsdon ME, Cistola DP. Discrete backbone disorder in the nuclear magnetic resonance structure of apo intestinal fatty acid-binding protein: implications for the mechanism of ligand entry. Biochemistry 1997;36:1450-1460. [PubMed: 9063893]

14. Jenkins AE, Hockenberry JA, Nguyen T, Bernlohr DA. Testing of the portal hypothesis: analysis of a V32G, F57G, K58G mutant of the fatty acid binding protein of the murine adipocyte. Biochemistry 2002;41:2022-2027. [PubMed: 11827549]

15. Hagan RM, Worner-Gibbs J, Wilton DC. Tryptophan insertion mutagenesis of liver fatty acid-binding protein: L28W mutant provides important insights into ligand binding and physiological function. $\mathrm{J}$ Biol Chem 2005;280:1782-1789. [PubMed: 15542605]

16. Falomir-Lockhart LJ, Laborde L, Kahn PC, Storch J, Corsico B. Protein-membrane interaction and fatty acid transfer from intestinal fatty acid-binding protein to membranes. Support for a multistep process. J Biol Chem 2006;281:13979-13989. [PubMed: 16551626]

17. Xiao H, Kaltashov IA. Transient structural disorder as a facilitator of protein-ligand binding: native $\mathrm{h} / \mathrm{d}$ exchange-mass spectrometry study of cellular retinoic acid binding protein I. J Am Soc Mass Spectrom 2005;16:869-879. [PubMed: 15907702]

18. Clark PL, Weston BF, Gierasch LM. Probing the folding pathway of a beta-clam protein with singletryptophan constructs. Fold Des 1998;3:401-412. [PubMed: 9806942]

19. Kleywegt GJ, Bergfors T, Senn H, Le Motte P, Gsell B, Shudo K, Jones TA. Crystal structures of cellular retinoic acid binding proteins I and II in complex with all-trans-retinoic acid and a synthetic retinoid. Structure 1994;2:1241-1258. [PubMed: 7704533]

20. Chrisman PA, McLuckey SA. Dissociations of disulfide-linked gaseous polypeptide/protein anions: ion chemistry with implications for protein identification and characterization. J Proteome Res 2002;1:549-557. [PubMed: 12645623] 
21. Budhu AS, Noy N. Direct channeling of retinoic acid between cellular retinoic acid-binding protein II and retinoic acid receptor sensitizes mammary carcinoma cells to retinoic acid-induced growth arrest. Mol Cell Biol 2002;22:2632-2641. [PubMed: 11909957]

22. Hemsley A, Arnheim N, Toney MD, Cortopassi G, Galas DJ. A simple method for site-directed mutagenesis using the polymerase chain reaction. Nucleic Acids Res 1989;17:6545-6551. [PubMed: 2674899]

23. Cogan U, Kopelman M, Mokady S, Shinitzky M. Binding affinities of retinol and related compounds to retinol binding proteins. Eur J Biochem 1976;65:71-78. [PubMed: 945163]

24. Clark PL, Liu ZP, Zhang J, Gierasch LM. Intrinsic tryptophans of CRABPI as probes of structure and folding. Protein Sci 1996;5:1108-1117. [PubMed: 8762142]

25. Fiorella PD, Giguere V, Napoli JL. Expression of cellular retinoic acid-binding protein (type II) in Escherichia coli. Characterization and comparison to cellular retinoic acid-binding protein (type I). J Biol Chem 1993;268:21545-21552. [PubMed: 8408005]

26. Noy N, Xu ZJ. Interactions of retinol with binding proteins: implications for the mechanism of uptake by cells. Biochemistry 1990;29:3878-3883. [PubMed: 2354158]

27. Zhang J, Liu ZP, Jones TA, Gierasch LM, Sambrook JF. Mutating the charged residues in the binding pocket of cellular retinoic acid-binding protein simultaneously reduces its binding affinity to retinoic acid and increases its thermostability. Proteins 1992;13:87-99. [PubMed: 1377826]

28. Creighton TE. Protein folding. Biochem J 1990;270:1-16. [PubMed: 2204340]

29. Zhang M, Kaltashov IA. Mapping of protein disulfide bonds using negative ion fragmentation with a broadband precursor selection. Anal Chem 2006;78:4820-4829. [PubMed: 16841900]

30. Noy N, Blaner WS. Interactions of retinol with binding proteins: studies with rat cellular retinolbinding protein and with rat retinol-binding protein. Biochemistry 1991;30:6380-6386. [PubMed: 2054343]

31. Herr FM, Li E, Weinberg RB, Cook VR, Storch J. Differential mechanisms of retinoid transfer from cellular retinol binding proteins types I and II to phospholipid membranes. J Biol Chem 1999;274:9556-9563. [PubMed: 10092641]

32. Sessler RJ, Noy N. A ligand-activated nuclear localization signal in cellular retinoic acid binding protein-II. Mol Cell 2005;18:343-353. [PubMed: 15866176]

33. Fogh K, Voorhees JJ, Astrom A. Expression, purification, and binding properties of human cellular retinoic acid-binding protein type I and type II. Arch Biochem Biophys 1993;300:751-755. [PubMed: 8382035]

34. Sanquer S, Gilchrest BA. Characterization of human cellular retinoic acid-binding proteins-I and -II: ligand binding affinities and distribution in skin. Arch Biochem Biophys 1994;311:86-94. [PubMed: 8185324]

35. Xiao H, Kaltashov IA, Eyles SJ. Indirect assessment of small hydrophobic ligand binding to a model protein using a combination of ESI MS and HDX/ESI MS. J Am Soc Mass Spectrom 2003;14:506515. [PubMed: 12745220]

36. Li H, Frieden C. NMR studies of 4-19F-phenylalanine-labeled intestinal fatty acid binding protein: evidence for conformational heterogeneity in the native state. Biochemistry 2005;44:2369-2377. [PubMed: 15709749]

37. Rajabzadeh M, Kao J, Frieden C. Consequences of single-site mutations in the intestinal fatty acid binding protein. Biochemistry 2003;42:12192-12199. [PubMed: 14567680]

38. Storch J, Veerkamp JH, Hsu KT. Similar mechanisms of fatty acid transfer from human anal rodent fatty acid-binding proteins to membranes: liver, intestine, heart muscle, and adipose tissue FABPs. Mol Cell Biochem 2002;239:25-33. [PubMed: 12479565]

39. Toke O, Monsey JD, Cistola DP. Kinetic Mechanism of Ligand Binding in Human Ileal Bile Acid Binding Protein as Determined by Stopped-Flow Fluorescence Analysis. Biochemistry. 2007

40. Tochtrop GP, DeKoster GT, Covey DF, Cistola DP. A single hydroxyl group governs ligand site selectivity in human ileal bile acid binding protein. J Am Chem Soc 2004;126:11024-11029. [PubMed: 15339188]

41. Lu J, Cistola DP, Li E. Two homologous rat cellular retinol-binding proteins differ in local conformational flexibility. J Mol Biol 2003;330:799-812. [PubMed: 12850148] 
42. Lu J, Lin CL, Tang C, Ponder JW, Kao JL, Cistola DP, Li E. Binding of retinol induces changes in rat cellular retinol-binding protein II conformation and backbone dynamics. J Mol Biol 2000;300:619-632. [PubMed: 10884357]

43. Lu J, Lin CL, Tang C, Ponder JW, Kao JL, Cistola DP, Li E. The structure and dynamics of rat apocellular retinol-binding protein II in solution: comparison with the X-ray structure. J Mol Biol 1999;286:1179-1195. [PubMed: 10047490]

44. Hodsdon ME, Cistola DP. Ligand binding alters the backbone mobility of intestinal fatty acid-binding protein as monitored by 15N NMR relaxation and 1H exchange. Biochemistry 1997;36:2278-2290. [PubMed: 9047330]

45. Zhang F, Lucke C, Baier LJ, Sacchettini JC, Hamilton JA. Solution structure of human intestinal fatty acid binding protein with a naturally-occurring single amino acid substitution (A54T) that is associated with altered lipid metabolism. Biochemistry 2003;42:7339-7347. [PubMed: 12809489]

46. Richieri GV, Low PJ, Ogata RT, Kleinfeld AM. Binding kinetics of engineered mutants provide insight about the pathway for entering and exiting the intestinal fatty acid binding protein. Biochemistry 1999;38:5888-5895. [PubMed: 10231541]

47. Clark PL, Liu ZP, Rizo J, Gierasch LM. Cavity formation before stable hydrogen bonding in the folding of a beta-clam protein. Nat Struct Biol 1997;4:883-886. [PubMed: 9360599]

48. Moghimi SM, Hunter AC, Murray JC. Nanomedicine: current status and future prospects. FASEB J 2005;19:311-330. [PubMed: 15746175]

49. Georgens C, Weyermann J, Zimmer A. Recombinant virus like particles as drug delivery system. Curr Pharm Biotechnol 2005;6:49-55. [PubMed: 15727555]

50. Lee LA, Wang Q. Adaptations of nanoscale viruses and other protein cages for medical applications. Nanomedicine 2006;2:137-149. [PubMed: 17292136] 

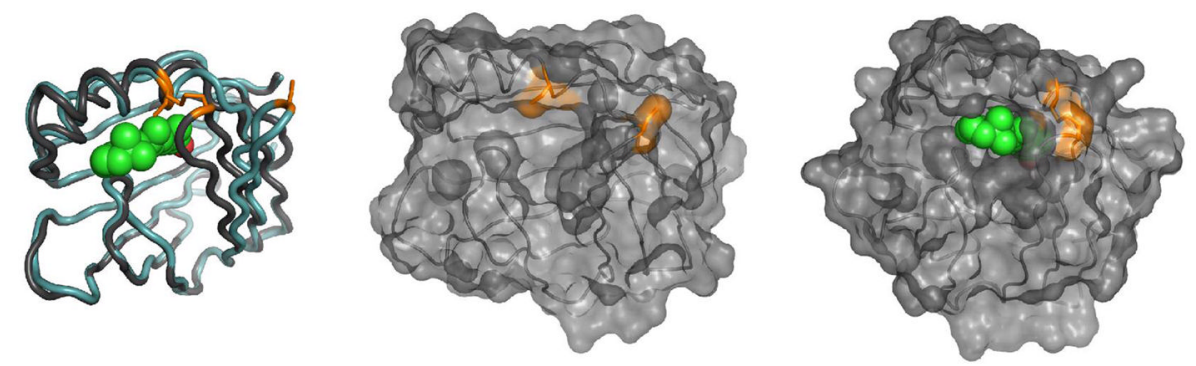

Figure 1.

Hypothetical structures of CRABP I A35C/T57C built on the CRABP I backbone (1CBI for the apo-form and 1CBR for the holo-form). Left: superimposed backbone traces of the apo(cyan) and holo- (gray) conformations of the protein. Center: surface model of the apo-CRABP I A35C/T57C with the introduced cysteine residues shown in orange. Right: model of the holoCRABP I A35C/T57C with the cysteine residues shown in orange and RA shown in green. 

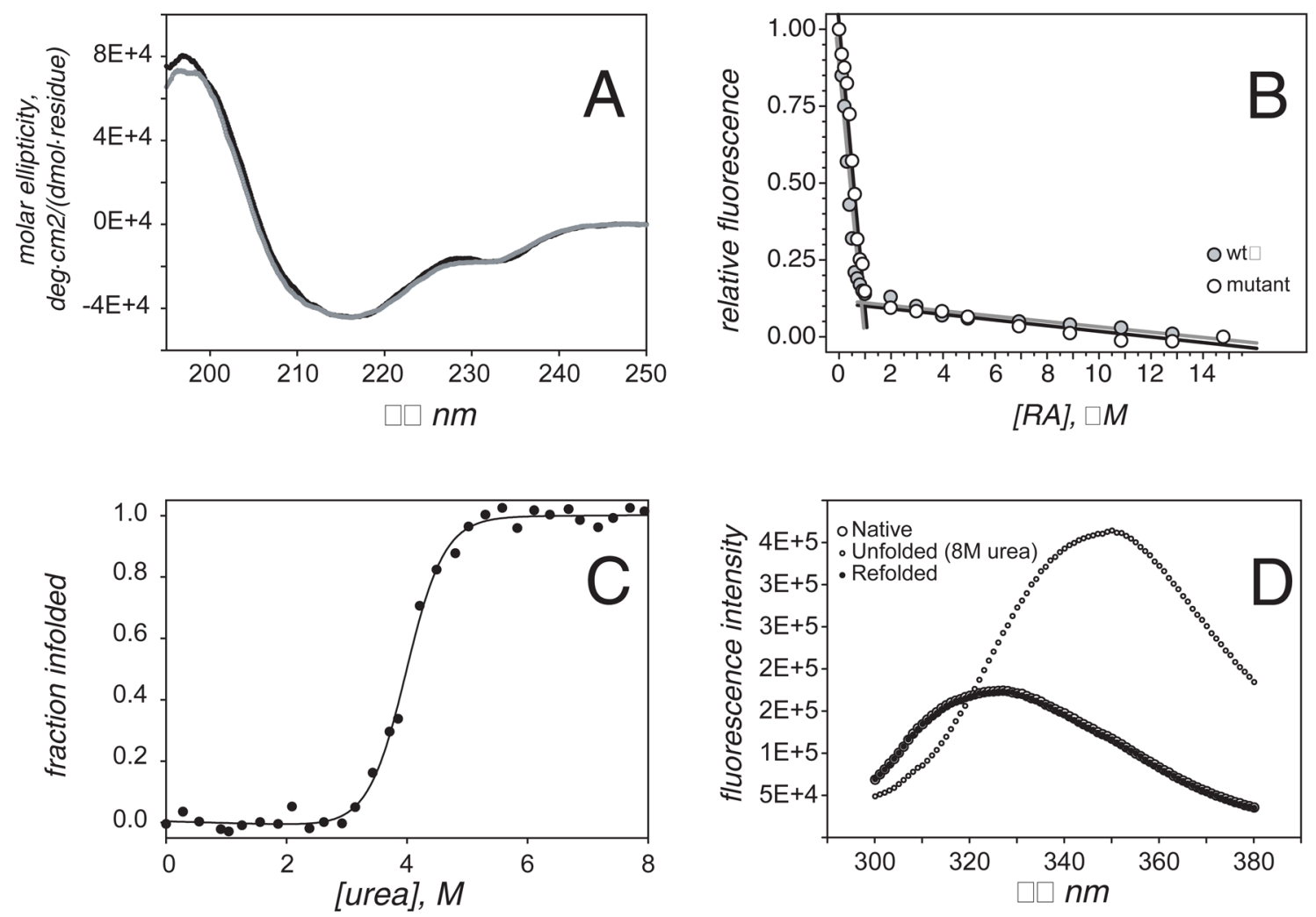

Figure 2.

Panel A: far-UV CD spectra of CRABP I (black trace) and CRABP I A35C/T57C (gray trace). For each spectrum, the protein concentration was $10 \mu \mathrm{M}$ and the buffer is $10 \mathrm{mM}$ sodium phosphate, $\mathrm{pH} 8.0$. The spectra were collected at $25^{\circ} \mathrm{C}$ and were baseline corrected by subtracting a blank spectrum. The spectra were collected for the apo-forms of the proteins. Panel B: Fluorimetric titration of CRABP I and CRABP I A35C/T57C with RA. The normalized fluorescence for each protein $(1 \mu \mathrm{M})$ at $328 \mathrm{~nm}$ in $10 \mathrm{mM}$ Tris $\mathrm{pH}$ 8.0. at room temperature in the presence of increasing amounts of RA is shown. Panel C: Urea-induced unfolding of CRABP I A35C/T57C. Denaturation was monitored as the change in the fluorescence emission intensity at increasing concentrations of urea $\left(10 \mu \mathrm{M}\right.$ protein, $\lambda_{\mathrm{ex}}=$ $280 \mathrm{~nm})$. Raw fluorescence was converted to the fraction of unfolded protein. Panel D: Fluorescence emission spectra of the mutant protein in the native form (black circles), denatured in $8 \mathrm{M}$ urea (open circles), and after refolding from $8 \mathrm{M}$ urea back to native conditions (gray triangles). 


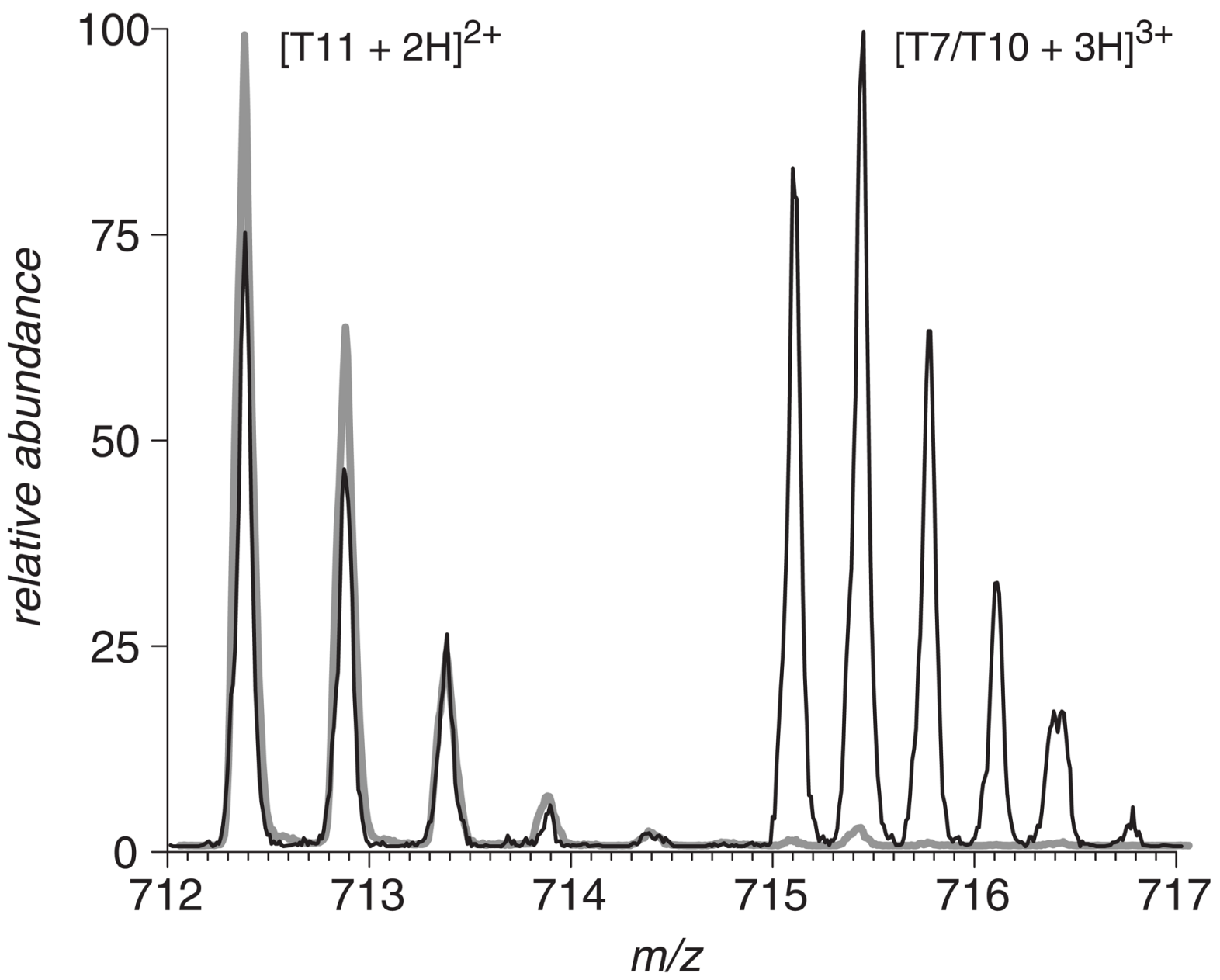

Figure 3.

Positive ion ESI MS of tryptic digests of apo- (gray trace) and holo- (black trace) CRABP I A35C/T57C showing $\mathrm{m} / \mathrm{z}$ region corresponding to the T11 and T7/T10 peptide fragments. 


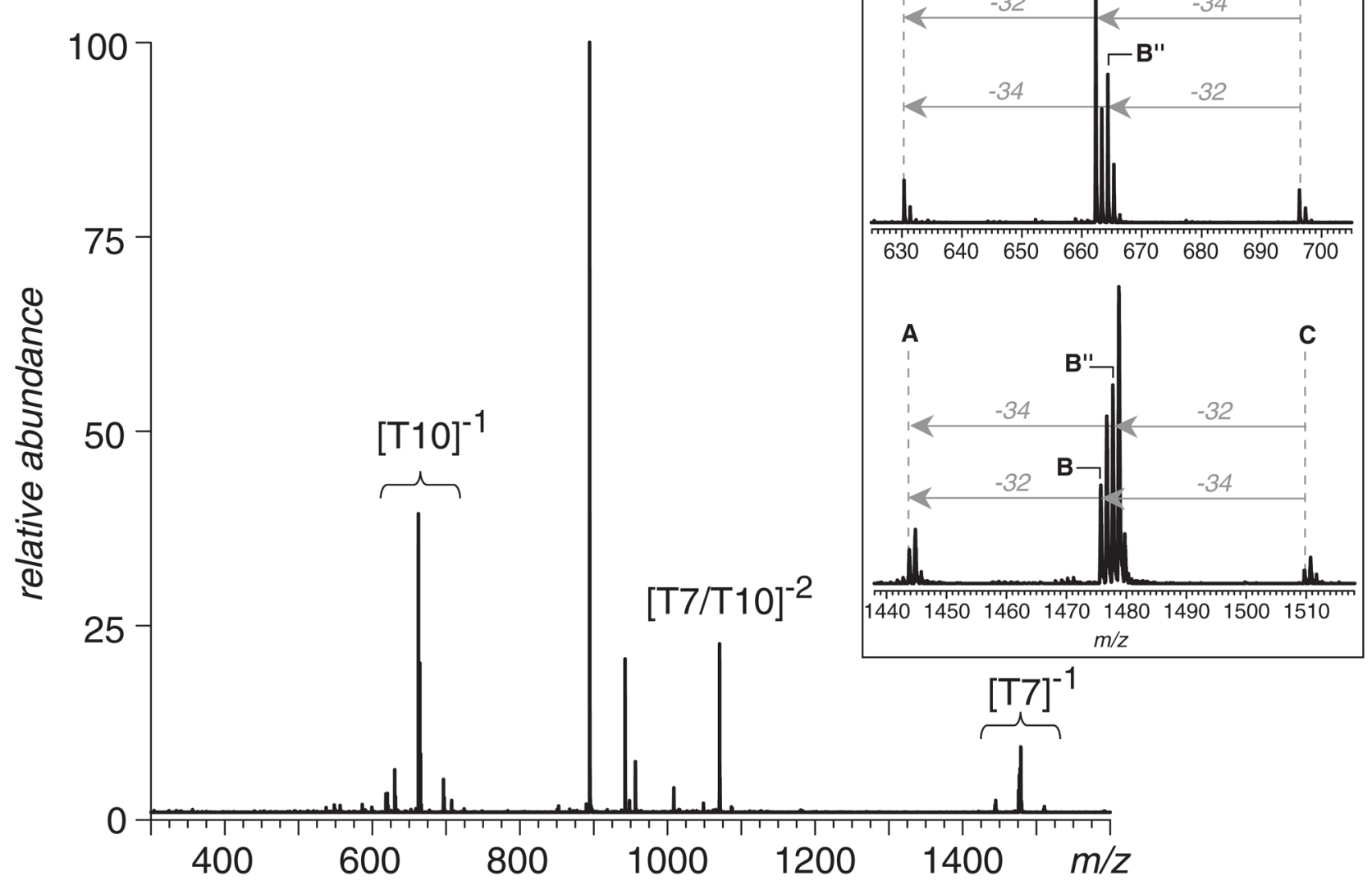

Figure 4.

Negative CAD MS of a doubly charged peptide dimer [T7/T10 - 2H ${ }^{2-}$ showing a characteristic dissociation pattern arising due to the gas phase cleavage of the disulfide bond connecting peptides T7 and T10. 

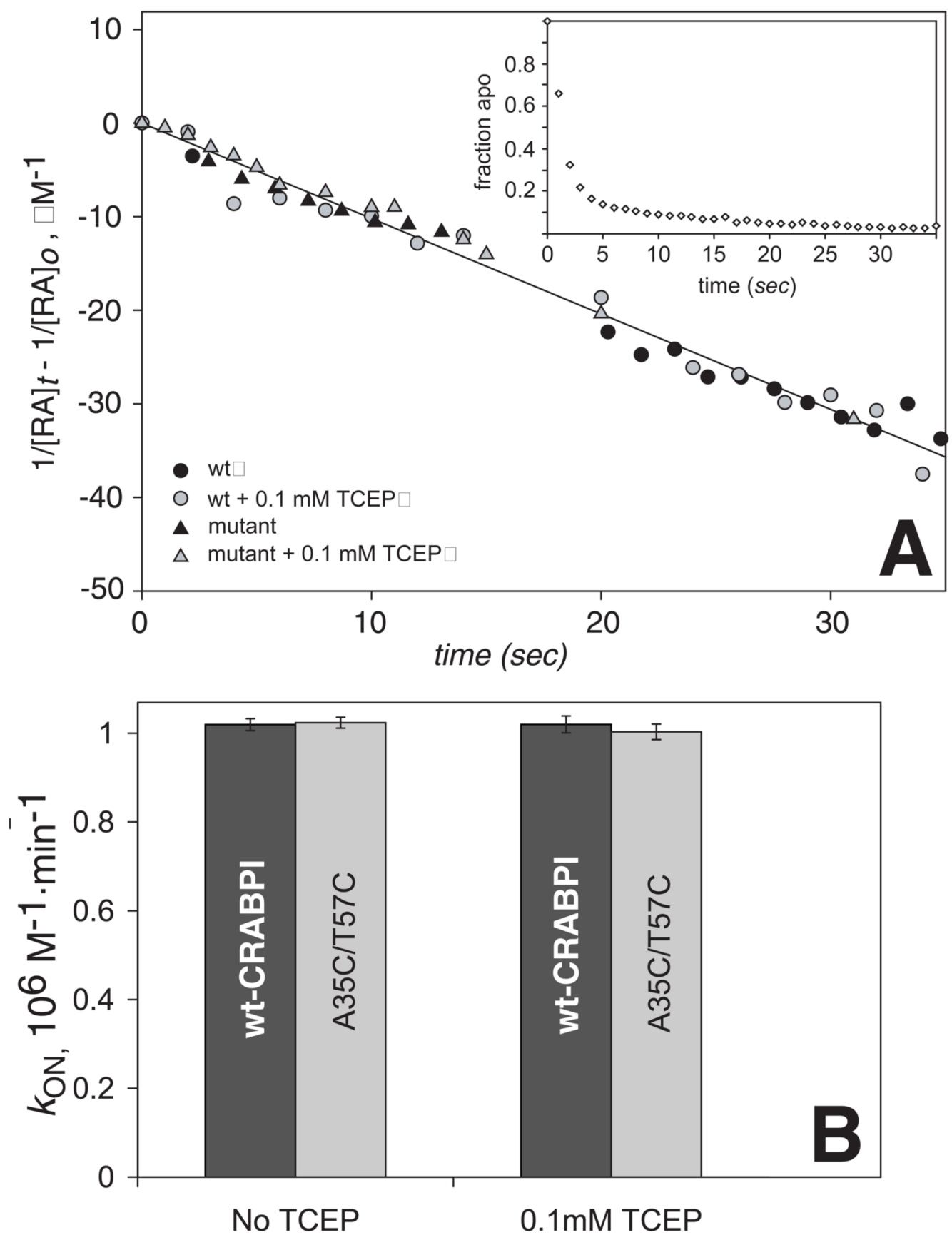

Figure 5.

(A) RA association with $w t$-CRABP I and CRABP I A35C/T57C in the presence and absence of the reducing agent. The slope of the plot is $k_{\mathrm{ON}}$, the rate constant of the association reaction (see the text for more detail). The insert shows the raw fluorescence data of the quenching of the protein due to the binding of RA. (B) The values of $k_{\mathrm{ON}}$ for $w t$-CRABP I (black bars) and CRABP I A35C/T57C (gray bars) in the absence and presence of the reducing agent. Each value is the result of four different experiments. 

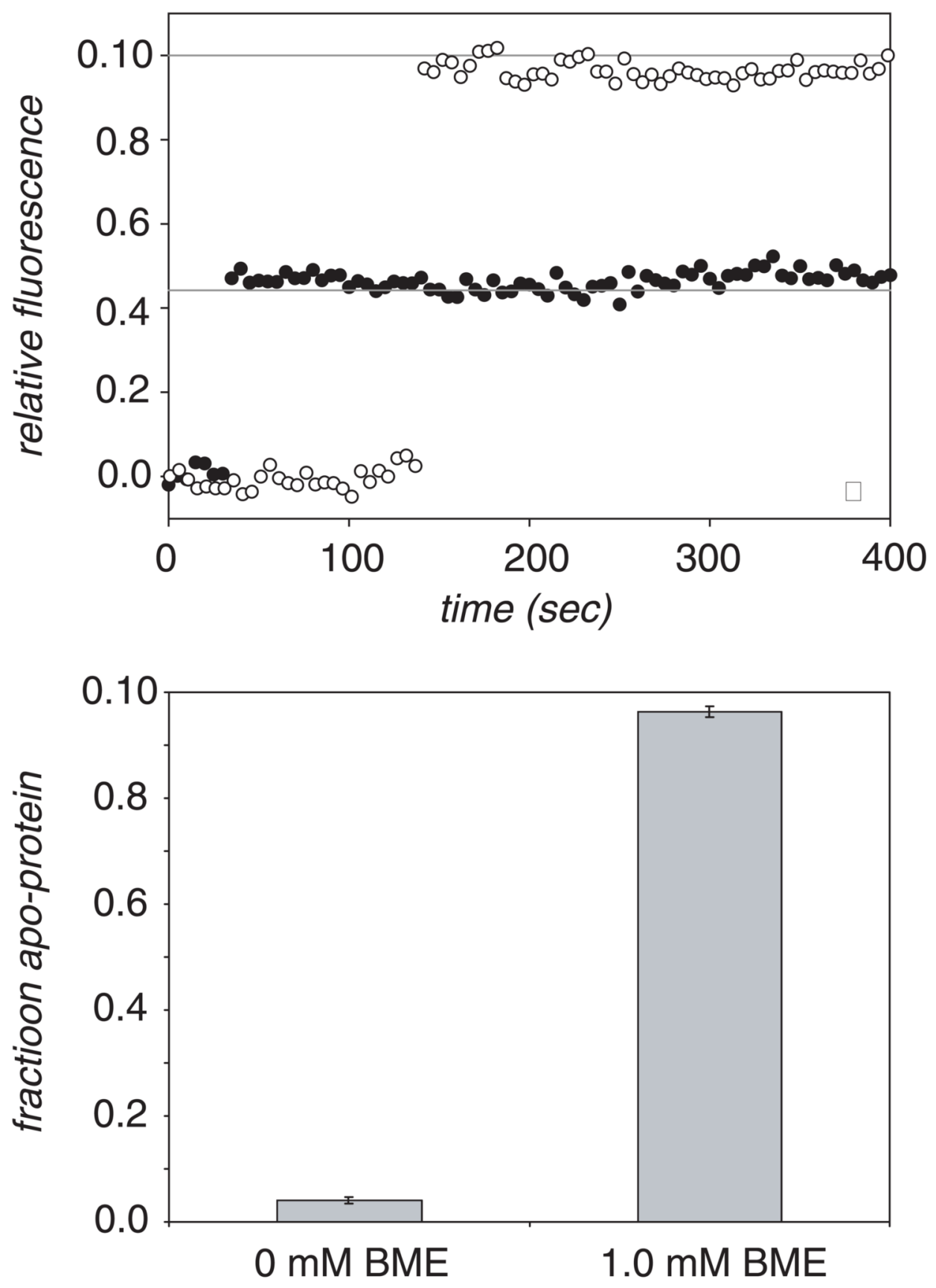

Figure 6.

(A) Fluorescence intensity change upon addition of holo-CRABP I A35C/T57C to the SUV with (gray) and without (black) protein reduction prior to its mixing with SUV. The two horizontal lines on the graph represent the fluorescence level of the apo- (lower) and holo(upper) form of the protein, which were calculated assuming no SUV-protein interaction. (B) RA partitioning between CRABP I A35C/T57C and SUV in the presence and absence of the reducing agent. The values are the average of 4 independent measurements. 


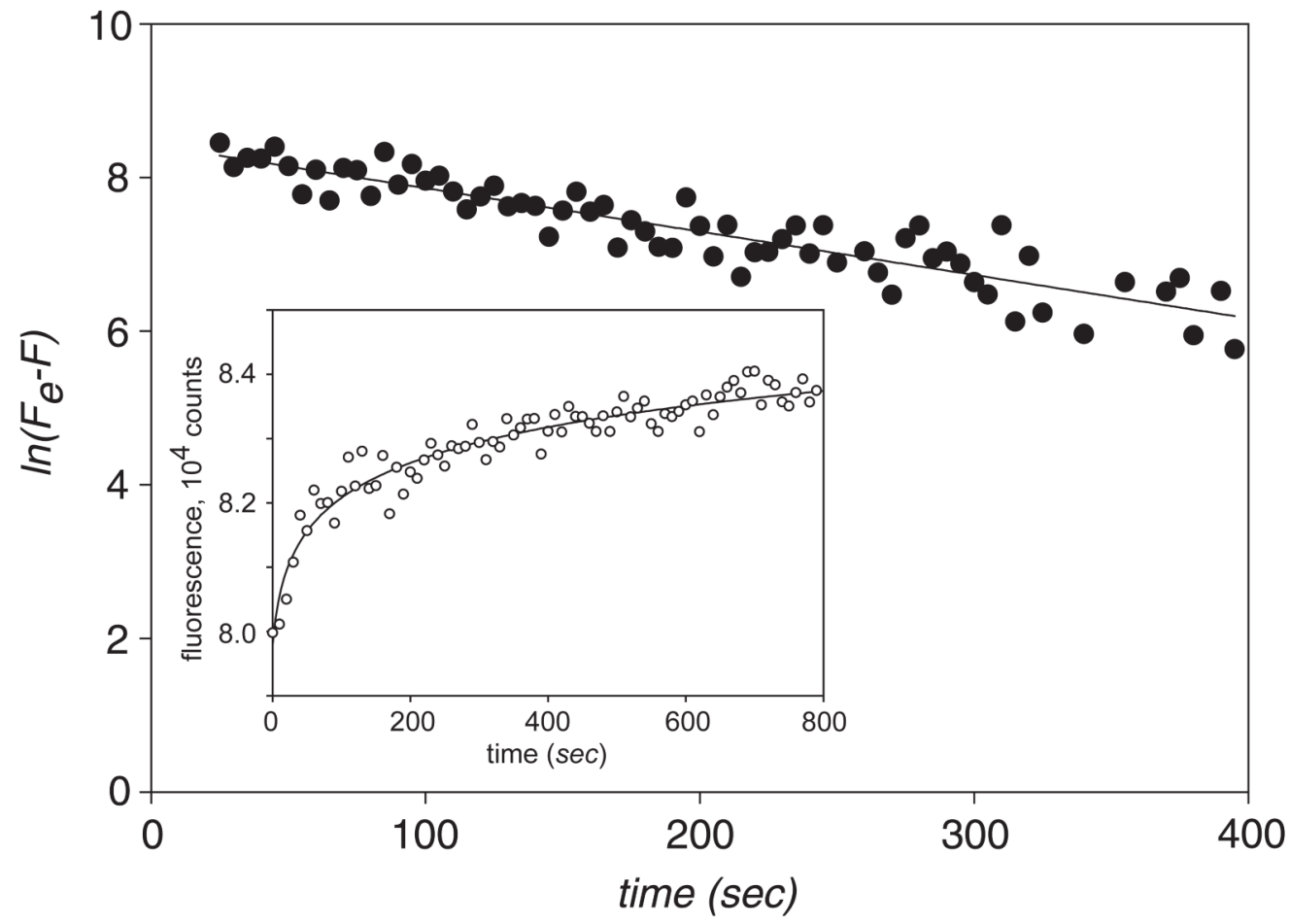

Figure 7.

Representative plot for the $k_{\mathrm{OFF}}$ measurement of RA from the reduced form of holo-CRABP I A35C/T57C. The insert represents the raw fluorimetric data of transfer of RA from the reduced mutant protein to the DOPC vesicles. 

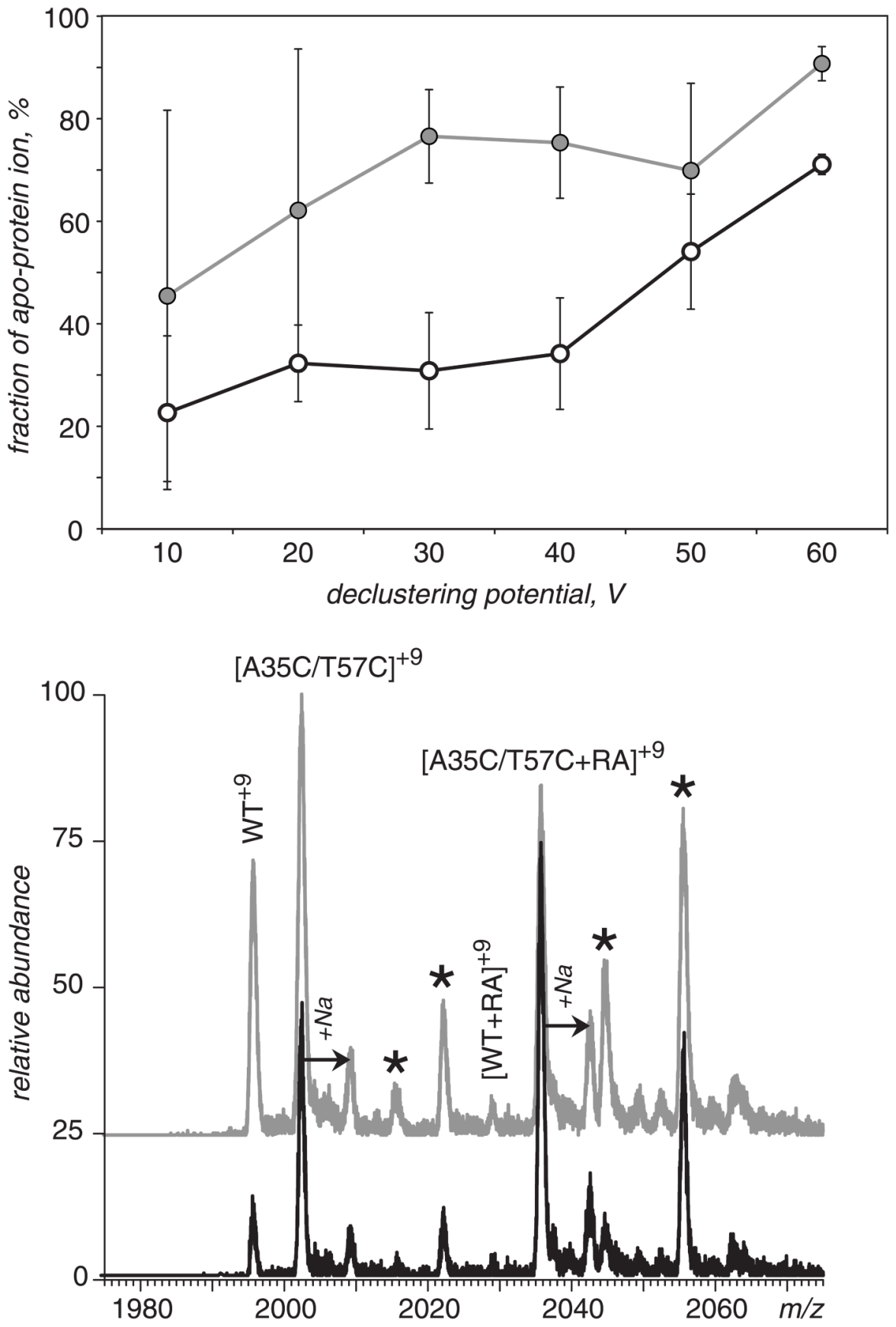

Figure 8.

Stability of CRABP I complex with RA in the absence of solvent. Top: fraction of dissociated complexes as a function of de-clustering potential in the ESI interface for the $w t$ - (gray circles) and the double mutant CRABP I (black circles). Bottom: a detailed view of the +9 region of the ESI mass spectra of holo-forms $w t$ - (gray trace) and the double mutant (black trace) CRABP I acquired at de-clustering potential $20 \mathrm{~V}$. 
Table 1

Kinetic and thermodynamic parameters of wt-CRABP I and the double mutant A35C/T57C

\begin{tabular}{|c|c|c|c|}
\hline \multirow{2}{*}{ Protein } & \multirow{2}{*}{$w$-CRABP } & \multicolumn{2}{|c|}{ A35C/T57C } \\
\cline { 3 - 4 } & & no reducing agent in apo or holo-forms & BME present in both forms \\
\hline$\Delta G, \mathrm{kcal} / \mathrm{mol}$ & $7.33 \pm 0.45$ & $7.29 \pm 0.55$ & not measured \\
\hline$m, \mathrm{kcal} /(\mathrm{mol} \cdot \mathrm{M})$ & $1.93 \pm 0.11$ & $1.89 \pm 0.13$ & not measured \\
\hline $\mathrm{C}_{m}, \mathrm{M}$ & $3.80 \pm 0.02$ & $3.86 \pm 0.03$ & $61.4 \pm 0.7$ \\
\hline$k_{\mathrm{ON}}, 10^{6}(\mathrm{M} \cdot \mathrm{min})^{-1}$ & $61.1 \pm 0.8$ & $60.2 \pm 1.1$ & $0.31 \pm 0.1$ \\
\hline$k_{\mathrm{OFF}}, \mathrm{min}^{-1}$ & $0.22 \pm 0.01$ & not measured & $5.05 \pm 0.10$ \\
\hline$K_{\mathrm{d}}, \mathrm{nM}$ & $3.6 \pm 0.12$ & not calculated & \\
\hline
\end{tabular}

$a_{\text {the }} \mathrm{OOFF}$ value for wt-CRABP I is taken from Dong, D., et al. (1999) J. Bio. Chem. 274, 23695 